\title{
OTRO APUNTE A LA ETAPA SEVILLANA DE ALONSO DE VANDELVIRA: LA PORTADA DE LA REAL AUDIENCIA
}

\author{
ANOTHER POINT TO ALONSO DE VANDELVIRA'S \\ SEVILLIAN PERIOD: THE ROYAL COURT MAIN DOOR
}

\author{
Francisco Javier Herrera García \\ Universidad de Sevilla, España \\ fjherrera@us.es
}

\begin{abstract}
En estas líneas ofrecemos el primer testimonio documental que vincula al cantero y arquitecto Alonso de Vandelvira con la confección de la portada de la antigua Real Audiencia de Sevilla, en 1606. Evaluamos la posible traza de la misma por Vermondo Resta, señalando como posible impulsor de esta obra al regente Antonio Corrionero, luego obispo de Canarias y Salamanca.

Palabras clave: Alonso de Vandelvira. Cantería. 1606. Vermondo Resta. Antonio Corrionero.

In these lines we offer the first documental report that link Alonso de Vandelvira, stonecutter and architect, with the construction of the monumental main door of the old sevillian Royal Court, in 1606. We review the Vermondo Resta work in the trace and pointing the regent Antonio Corrionero, after Canary Is. and Salamanca bishop, as possible project developer.

Keywords: Alonso de Vandelvira. Stonecutter. 1606. Vermondo Resta. Antonio Corrionero.
\end{abstract}

En estas mismas páginas dimos a conocer algunos datos sobre la etapa sevillana (1588-1609) de Alonso de Vandelvira, reflexionando sobre el contacto permanente y obligaciones que mantuvo con su tierra giennense, las nuevas perspectivas en el litoral atlántico gaditano que se vaticinan desde Sevilla, así como profundizamos en dos empresas arquitectónicas en las que intervino: la construcción de la lonja de mercaderes y la portada del convento de Santa Isabel ${ }^{1}$.

Como quiera que el inmenso caudal documental de los protocolos notariales sevillanos no deja de ofrecer datos inéditos, ahora analizamos una noticia que

${ }^{1}$ HERRERA GARCÍA, Francisco Javier: "La etapa sevillana de Alonso de Vandelvira (1588-1609). Nuevas aportaciones”, Laboratorio de Arte, 26, 2014, pp. 95-119. 
puede revestir gran interés, como es la relación del arquitecto con la portada principal de la Real Audiencia de Sevilla, aún conservada en el actual edificio, si bien desplazada de su situación original y quizás algo transformada, al menos en su cuerpo superior. Como ya expresó Alfredo Morales, el inmueble que hoy tenemos es un auténtico "palimpsesto"2 donde resulta difícil reconocer su trayectoria constructiva, que arranca en tiempos bajomedievales, se perpetúa en el XVI, adquiere especial intensidad entre 1595-1606, cuando el edificio se adapta a criterios de funcionalidad y estética propios de la arquitectura manierista, para sufrir nuevamente profundas remodelaciones y algunos contratiempos en el transcurso de los siglos XIX y XX, derivando en su actual fisonomía caracterizada por el predominio de préstamos historicistas, sobre todo en la vistosa fachada.

Tres son los elementos subsistentes de las reformas que ahora nos interesan, las que tuvieron lugar entre 1595 y 1606: el patio central con sus galerías de arcos, la escalera y la portada. Significaron los trabajos de aquellos años la puesta al día del viejo edificio y añadieron presencia monumental a su fachada, abierta al centro neurálgico de la ciudad, la plaza de San Francisco. En un principio, la portada sabemos que se encontraba desplazada hacia el extremo izquierdo del inmueble, de acuerdo a criterios de funcionalidad y marcando un recorrido en ángulo recto para acceder al patio y escalera principal. Así la muestran la planta de la plaza del año 1730 y la vista de la real mascarada de 1747 , patrocinada por la Real Fábrica de Tabacos e inmortalizada por el pintor Domingo Martínez. Sería hacia $1818^{3}$, cuando pasa a ocupar su actual posición central, en el transcurso de unas obras que no eran más que el inicio de las profundas transformaciones que afectarían al complejo desde entonces si bien, en esencia, no parece que este pórtico experimentara alteraciones notables, según veremos. Era la principal de las aberturas de una fachada que delataba, a juzgar por las fuentes gráficas citadas, la impronta de la herreriana lonja de mercaderes, actual Archivo General de Indias ${ }^{4}$.

Tales paralelismo formales y el hecho de que fuera, el de la Audiencia, un edificio de patrocinio real, sirvió para que la fachada se relacionara, junto al patio y escalera, con la actividad proyectual de los arquitectos vinculados a la lonja, especialmente Juan de Minjares a quien Teodoro Falcón asigna el proyecto del patio y la escalera. Fallecido el arquitecto cortesano en 1599 y sustituido en la principal de sus obras por Alonso de Vandelviera, Falcón dio por seguro que este sería el maestro de la segunda fase de aquellos trabajos, en torno a 1606, cuando

${ }^{2}$ MORALES MARTÍNEZ, Alfredo: "Noticias sobre la construcción del patio de la Real Audiencia de Sevilla", Laboratorio de Arte, 10, 1997, pp. 403-411; de la cita p. 403.

${ }^{3}$ FALCÓN MÁRQUEZ, Teodoro: El palacio Caja San Fernando: antigua Real Audiencia de Sevilla. Sevilla, 1993, p. 12.

${ }^{4}$ Ibídem, p. 12. 
efectivamente se construye la portada de ingreso, según señala la inscripción todavía subsistente, no sin antes haber intervenido en las obras del propio patio ${ }^{5}$.

Aportación significativa, al menos en cuanto al patio se refiere, es la que hace Alfredo Morales dando a conocer un contrato relacionado con la construcción de uno de los frentes de aquel espacio, en 1596, obra que acometen los canteros Mateo Esteban y Diego de Caraballo, a la vez que desestima su vinculación con modelos de Andalucía Oriental, como se había sugerido, para emparentarlo con la tradición sevillana consecuente con la huella de Hernán Ruiz II. Propone Morales, además, la indudable autoría de Vermondo Resta, desde 1603 maestro mayor de los Reales Alcázares, para las trazas y condiciones del patio y fachada ${ }^{6}$.

Nuestra contribución se centra fundamentalmente en la carta de pago que el 28 de enero de 1606 otorgaba Vandelvira al escribano y "depositario de los maravedís y penas de obra" de la Real Audiencia, de 300 reales, parte del pago que le corresponde por la labor de cantería que desarrolla en la portada, según libranza del regente Antonio Corrionero 7 . Todo concuerda, al menos en lo que a cronología y gerentes de la obra respecta, con lo anunciado en la cartela provista en el cuerpo superior del pórtico ${ }^{8}$. Así las cosas, estamos ante el primer documento que prueba la intervención de Alonso de Vandelvira en las labores de cantería de la Audiencia, en concreto de su pórtico, que debió confeccionarse entre 1605 y $1606^{9}$. A comienzos de este último año debieron estar concluidas las operaciones referidas, pues sabemos que de inmediato el ubetense inicia la construcción de la

${ }^{5}$ Ibíd. pp. 10-11. FALCÓN MÁRQUEZ, Teodoro: El Emporio de Sevilla. IV centenario de la construcción de la Real Audiencia. Sevilla, 1995, s/p.

${ }^{6}$ MORALES MARTÍNEZ, Alfredo: "Noticias sobre la construcción...", op. cit., pp. 406-407. Una buena síntesis de estas teorías pude verse en CRUZ ISIDORO, Fernando: Alonso de Vandelvira (1544-ca. 1626/7). Tratadista y arquitecto andaluz. Sevilla, 2001, pp. 106-109.

7 1606-I-28. Alonso de Vandelvira maestro de cantería vecino de Sevilla en la collación de Santa María, otorga carta de pago a Francisco de Porras Sabariego, escribano de la real audiencia de esta ciudad, depositario de los maravedís de penas de obras de la Real Audiencia, de 300 reales en cuenta de lo que se le debe, por la obra de cantería que está haciendo en la portada del edificio sede de la justicia real, en virtud de una libranza del regente Antonio Corrionero. Entre los testigos figuran Diego Carballo, cantero, y Miguel Asensio. Archivo Histórico Provincial de Sevilla, secc. Notarías de Sevilla, leg. n 1.139, of $^{\mathrm{D}} 2$, fol. $556 \mathrm{v}$.

${ }^{8}$ REINANDO LA C.R.M. EL / REY D. PHELIPE III N ${ }^{\circ}$. SEÑOR / Y SIENDO REGENTE DES- / -TA R. AUDIENCIA EL D. I ANTONIO CORRIONERO / SE HIÇO ESTA OBRA / AÑO DE MDCVI.

${ }^{9}$ Una lacónica noticia de Tenorio indica que la actual portada venía a sustituir unos soportales anteriores, que servían de acceso al edificio. TENORIO, Nicolás: Noticia histórica de la Real Audiencia de Sevilla. Sevilla, 1924, p. 27. 
portada del convento de Santa Isabel, para la que dicta condiciones y encarga la piedra a las canteras de martelilla de Puerto Real ${ }^{10}$.

Una cuestión que no podemos pasar por alto, es la referida a la autoría de las trazas, sobre la que se han interrogado quienes nos han precedido en la cuestión, según hemos avanzado. El documento que citamos presenta a Alonso de Vandelvira como ejecutor, si acaso director de las operaciones constructivas. Nada dice respecto a condiciones y, menos aún, trazas. No conocemos documentación de la época en la que Vandelvira figure nombrado maestro mayor vinculado a la Real Audiencia, cargo posiblemente no definido en ese momento ${ }^{11}$, mientras a partir de 1599 se proclama repetidamente "maestro mayor de obras de la lonja". No parece probable que interviniera en trazas destinadas a las casas de la justicia, labores que debieron estar en manos de arquitectos reales, como el expresado Juan de Minjares, en un primer momento y, desde 1603, el milanés Vermondo Resta, maestro mayor de los Reales Alcázares.

Hasta ahora, las propuestas en relación con la traza de la portada, han oscilado entre Alonso de Vandelvira, a quien la asignan Ana Marín y Teodoro Falcón ${ }^{12}$ y Vermondo Resta, por quien se inclinan Alfonso Jiménez y Alfredo Morales ${ }^{13}$. Sintomático es también que entre los testigos de la carta de pago aludida, se encuentre el cantero Diego de Caraballo o Carballo, ejecutor según dijimos de una de las pandas de arcos del patio, en 1596, luego vinculado a la obra de la portada del apeadero del Alcázar, en 1607, proyecto de Vermondo Resta ${ }^{14}$. Precisamente, la comparación con esta puerta, cuyas obras transcurren entre 1607 y 1609, permite fortalecer la idea de que fuera el milanés autor de la traza de la portada de la Audiencia, a todas luces antecedente inmediato de la que da acceso al apeadero, espacio calificado como una de las obras claves de la arquitectura 111.

${ }^{10}$ HERRERA GARCÍA, Francisco Javier: "La etapa sevillana...”, op. cit., pp. 106-

${ }^{11}$ Entre las noticias analizadas de principios del siglo XVII, no consta en Sevilla maestro mayor alguno vinculado a la Real Audiencia. PLEGUEZUELO, Alfonso: Arquitectura y construcción en Sevilla (1590-1630). Sevilla, 2000, pp. 35-38. En las Ordenanzas de la Audiencia de 1603, reeditadas en 1639 no figura ese cargo en la plantilla de la corporación. Únicamente parece que se regulariza a partir de 1684, cuando fue nombrado maestro mayor de obras de la Real Audiencia, Juan Navarro "el mayor". OLLERO LOBATO, Francisco: "La maestría mayor de obras de la Real Audiencia de Sevilla (siglos XVII-XIX)", Atrio. Revista de Historia del Arte, 18, 2012, pp. 27-42; de la cita p. 29.

12 MARÍN FIDALGO, Ana: Vermondo Resta. Sevilla, 1988, p. 31. FALCÓN MÁRQUEZ, Teodoro: El palacio... op. cit., p. 11.

13 JIMÉNEZ MARTÍN, Alfonso: "Resta, Vermondo", Gran Enciclopedia de Andalucía, vol. VI, Sevilla, 1979, p. 2827. MORALES MARTÍNEZ, Alfredo: "Noticias sobre la construcción...”, op. cit. p. 407.

${ }^{14}$ MARÍN FIDALGO, Ana: El Alcázar de Sevilla bajo los Austrias. Sevilla, 1990, t. II, pp. 366-367 y 750 . 
manierista sevillana, de evidentes consecuencias posteriores, en la ciudad y su entorno. Las obras de cantería del apeadero fueron concertadas con Diego Carballo el 28 de Julio de 1607, utilizándose para las labores del pórtico, piedra de las canteras de Espera (Cádiz) ${ }^{15}$.

La confeccionada por Vandelvira en la Audiencia consiste en un vano adintelado recercado por una moldura que en los ángulos se resuleve en orejetas. Ligeramente retranqueadas, a ambos lados figuran desnudas pilastras toscanas con sus respectivos capiteles. A plomo con las jambas sobresalen dos vistosas ménsulas de talón que soportan la cornisa caneada. Ménsulas parecidas encontramos en otras ocasiones en obras relacionadas con Alonso de Vandelvira, quizás trazadas por Resta, como en las portadillas del coro del convento de Santa Isabel ${ }^{16}$. El amplio friso permite ubicar una cartela de perfiles recortados, lisa, sin ningún género de añadido ornamental. La volada cornisa sirve de repisa al balcón, compuesto también por una abertura adintelada entre pilastras, más estrechas que las inferiores, pero con juego de adelantamiento y retranqueo y ménsulas en línea con las descritas. La cartela, esculpida con la leyenda ya indicada, está acompañada con el escudo de la ciudad, de factura moderna ${ }^{17}$.

La portada del apeadero del alcázar repite idéntico esquema, caracterizado por la desnudez ornamental, las potentes ménsulas, la moldura orejada, la cartela de lados quebrados y, en este caso, resulta más acusado el adelantamiento del hueco enmarcado con la moldura, respeto a las columnas laterales, que pretenden un orden simbiótico dórico - toscano. Tales esquemas debieron surtir acusado efecto en la obra de Vandelvira quien, poco después, entre 1610 y 1614 lo aplica a la portada del evangelio del santuario de la Caridad de Sanlúcar de Barrameda ${ }^{18}$.

Los préstamos que toma Resta de Vignola, bien inspirados en la arquitectura de Miguel Ángel o en edificios de época romana, son innegables. Así, las columnas del apeadero, adoptan una de las versiones del dórico examinadas por el arquitecto y tratadista italiano, y el retranqueamiento concuerda con su apreciación de

${ }^{15}$ Ibídem, pp. 366-367 y 369-370.

${ }_{16}$ Aunque muy transformada y actualmente desaparecida, pero conocida por antiguas fotografías, la sencilla portada que daba acceso a la capilla del hospital de San Hermenegildo, desde 1846 asilo de la mendicidad de San Fernando, fue ideada de acuerdo a un esquema semejante pero más simplificado, con estrechas pilastras que culminaban en ménsulas vegetales y moldura orejeada. Sabemos que fue construida, al igual que la capilla a la que daba acceso, entre 1601 y 1604, según proyecto de Alonso de Vandelvira. HERRERA DÁVILA, Joaquín: El Hospital del Cardenal de Sevilla y el Doctor Hidalgo de Agüero. Sevilla, 2010, p. 61.

${ }^{17}$ Las pilastras pareadas laterales son producto de reformas cercanas a nuestros días, y tampoco pertenecen a los momentos que analizamos el águila bicéfala superior ni el escudo de la ciudad que en parte oculta la cartela de este cuerpo. La primera es posible que fuera reaprovechada de las reformas introducidas en el siglo XVI, en época de Carlos V.

${ }^{18}$ CRUZ ISIDORO, Fernando: Alonso de Vandelvira ..., op. cit., pp. 195-200. 
atribuir a Miguel Ángel la primicia en la invención del recurso, asegurando que ...fu il primo che a nostri tempi usasse di fare chele colonne londe si ascondessero nel muro ${ }^{19}$. La solución de retrasar los soportes, tendrá notable éxito en la retablística sevillana de finales del XVI y comienzos del XVII, según vemos en numerosos retablos de Bautista Vázquez "el viejo", Juan de Oviedo "el joven” o Martínez Montañés. Quizás, retrasar los soportes, potenciaba la visión de las imágenes dispuestas en los recuadros, bien fueran altorrelieves o pinturas.

Los recuadros - cartelas insertos en los frisos para ser provistos de inscripciones, o como mero objeto decorativo, muy presentes en los retablos de Montañés, así como las molduras enmarcando el vano también parecen seguir principios miguelangelescos a través de Vignola, como podemos comprobar en relación con las ilustraciones que nos ofrece la "Regola delli cinque ordini" de la puerta principal de acceso al "ricetto" de la Biblioteca Laurenziana ${ }^{20}$.

De esta manera, documentada la intervención de Alonso de Vandelvira como director de la obra de la portada de la antigua Audiencia sevillana, hay razones para sospechar que su actividad en aquel edificio pudo ser de mayor envergadura, quizás como ya se ha expuesto, siguiendo ideas de Minjares en una primera etapa y, tal como parece lógico, a las órdenes del milanés Vermondo Resta, quien haciendo uso de preceptos vignolescos y manieristas en general, alcanzó a definir un modelo de pórtico austero y a la vez elegante, que señala el tránsito a tipologías de creciente empaque barroco.

No pondremos punto final a estas líneas sin antes recordar la importancia que en obras de este tipo tuvieron las máximas autoridades de la institución real, en este caso el regente, o presidente de la Audiencia ${ }^{21}$, cuyo nombre figura tanto en el documento citado como en la cartela del cuerpo superior de la portada, el Doctor Antonio Corrionero ${ }^{22}$. En sus manos estuvo el impulso y gestión

${ }^{19}$ Se refiere a una de las puertas del convento de Santa Apolonia de Florencia, parece que proyectada por Miguel Ángel. BAROZZIO DA VIGNOLA, Iacomo: Regola delli cinque ordini d'architettura di..., Roma, 1562. Edición facsímil de la Editorial de la Universidad Politécnica de Valencia, 2002, fol. 87r.

${ }^{20}$ Ibídem, fol. $88 \mathrm{r}$.

${ }^{21}$ Las autoridades judiciales estaban encabezadas por el regente, además componían la Audiencia ocho oidores, un fiscal y número variable de relatores, receptores, escribanos, alguaciles y porteros. FALCÓN MÁRQUEZ, Teodoro: El emporio..., op. cit., s/p. Otro cargo que figura en el documento es la figura de Francisco de Porras Sabariego, escribano, depositario de las partidas destinadas a las obras y pagador de las mismas, quien abona los emolumentos a Alonso de Vandelvira. Era otra de las figuras habituales en las obras de relieve, en edificios vinculados a la administración real. PLEGUEZUELO, Alfonso: Arquitectura y construcción... op. cit., pp. 67-68.

${ }^{22}$ Fue regente hasta el 26 de marzo de 1615, según informa Santos Torres, quien erróneamente lo califica de licenciado, en lugar de doctor. SANTOS TORRES, José: Historia de la Real Audiencia de Sevilla. Sevilla, 1986, p. 57. 
económica de las obras que ahora se acometen, pero desconocemos el grado de implicación en las mismas, para decidir artífices, elegir o supervisar trazas, etc ${ }^{23}$. Sabemos que era natural de la villa de Babilafuente (Salamanca), donde nació hacia 1554. En Salamanca inició sus estudios y luego sería becario del célebre Colegio de la Santa Cruz de Valladolid, ciudad de cuya universidad fue catedrático. Llegó a convertirse en una personalidad eminente, distinguido jurista y eclesiástico de relieve, lo que daría lugar a su designación para importantes cargos tanto en el campo judicial como en el eclesiástico. Antes de llegar a Sevilla fue provisor y vicario general de Cuenca, auditor de las Reales Chancillerías de Granada y Valladolid y, ya en territorio hispalense, lo tenemos desde algunos años antes de 1606 de regente de la Real Audiencia ${ }^{24}$, máxima autoridad del organismo regio $^{25}$. Dentro de la iglesia, los ministerios de mayor relieve de cuantos disfrutó, fueron los de obispo de Canarias, para cuya sede fue nombrado en 1614, permaneciendo en ella hasta 1621, año en el que sería designado prelado de Salamanca, donde fallece en $1633^{26}$.

Merece destacarse su faceta como promotor de empresas artísticas. No cabe duda que en Sevilla, nada más conocer su designación para el obispado canario, en octubre de 1614, se ocuparía de acelerar la finalización de dos importantes encargos que ese año se acometían en talleres hispalenses para el cabildo de la catedral de Santa Ana de Las Palmas: las andas o custodia de plata del corpus y una

${ }^{23}$ Si hacemos caso de Álvarez Jusué, bajo la regencia de Corrionero tuvo lugar igualmente, la construcción de la escalera. Apuntamos la posibilidad de que en la misma interviniera también el cantero y arquitecto ubetense. ÁLVAREZ JUSUÉ, Aurelio: Biografía de una Audiencia. El Tribunal del Rey en Sevilla. Sevilla, 1956, p. 34, trabajo inédito citado por SANTOS TORRES, José: Historia ... op. cit., pp. 59-60.

${ }^{24}$ Debió producirse su toma de posesión como regente de la Audiencia sevillana, después de 1603, pues en las ordenanzas impresas ese año, en ningún caso es citado Antonio Corrionero. Ordenanças de la Real Audiencia de Sevilla. Sevilla, 1603 (reed. Guadalquivir, 1995).

${ }^{25}$ Debió residir en la planta alta, según era costumbre para los regentes, lo cual pudo servir de acicate para acelerar los trabajos de la que, a fin de cuentas, era su propia residencia palatina. GONZÁLEZ DE LEÓN, Félix: Noticia artística de todos los edificios públicos... de Sevilla. Sevilla, 1844 (reed. De 1973), p. 72.

${ }^{26}$ CAZORLA LEÓN, Santiago y SÁNCHEZ RODRÍGUEZ, Julio: Obispos de Canarias y Rubicón. Madrid, 1997, pp. 187-188. RUBIO MERINO, Pedro: "Presentación del doctor don Antonio Corrionero para el obispado de Canarias (1614)", en VIII Coloquio de Historia Canario-Americana, vol. 2, Las Palmas de Gran Canaria, 1991, pp. 847-870. Su lápida sepulcral de la capilla de la Verdad, en la catedral nueva de Salamanca, sintetiza sus principales cargos y distinciones: Aquí yaze el ilustrísimo señor don Antonio Corrionero, fundador de esta capilla, fue colegial del mui insigne collegio de Santa Cruz de Valladolid, oydor de la real chancillería de Granada y de Valladolid, regente de Sevilla y obispo de Canaria y Salamanca y del Consejo de su Magestad. Falleció año de 1633 a 4 de Abril del dicho año. 
colección de cantorales iluminados para las principales festividades de la iglesia mayor grancanaria, escasa en este tipo de bienes litúrgicos y suntuarios, después del destructivo ataque del pirata holandés Pieter van der Does, en 1599. El obispo arriba a la capital grancanaria el 15 de abril de 1615, llevando a buen recaudo en su navío la citada custodia y los libros cantorales ${ }^{27}$, algunos firmados por el "escritor de libros" activo entonces en Sevilla, Simón Rodríguez Carballo, conservados en la actualidad ${ }^{28}$. Para ello resultó vital la intermediación del ministril de la catedral sevillana Jerónimo de Medina, agente de los capitulares canarios.

Lejos del Archipiélago, no olvidó a la Virgen del Pino de quien fue devoto distinguido ${ }^{29}$ pues, ya en Salamanca, envió una lámpara de regalo a la iglesia de Teror donde recibe culto la imagen mariana. Sin embargo, la mayor de sus empresas artísticas se encuentra en la catedral nueva salmantina, la capilla de Nuestra Señora de la Verdad. Allí donde está sepultado en unión de otros familiares. Se comenzó a construir en 1628 y en ella figura su sepulcro con escultura yacente y un interesante lienzo, obra de Pedro de Parada (1630), donde se retrata en unión de otros familiares eclesiásticos, en actitud de adorar a Cristo crucificado ${ }^{30}$.

Por último, a modo de epílogo de estas breves líneas, el citado Antonio Corrionero, regente de la Audiencia de Sevilla y obispo de Canarias y Salamanca, debió ser tío de Juan Ruano y Corrionero, hijo este último de Diego Ruano Corrionero, sin duda hermano de nuestro prelado y Juana Toribio. Juan Ruano nació en Salamanca en 1618. fue promovido a las diócesis de Cefalú en 1659 y a la de Monreale (ambas en Sicilia) en $1672^{31}$, catedral esta última donde labró su capilla de enterramiento dedicada al "Santo Crocefisso", obra cumbre del barroco siciliano, dentro de la tendencia de embutidos de mármoles de colores, "marmi mischi e tramischi”, pero esta es otra historia.

Fecha de recepción: 20 de septiembre de 2014

Fecha de aceptación: 28 de noviembre de 2014

${ }^{27}$ CAZORLA LEÓN, Santiago: Historia de la Catedral de Canarias. Las Palmas de Gran Canaria, 1992, pp. 311 y 362.

${ }^{28}$ SIEMENS HERNÁNDEZ, Lothar, "Cantoral de canto llano...", en cat. exp. La huella y la senda, Islas Canarias, 2004, pp. 547-554.

${ }^{29}$ SÁNCHEZ RODRÍGUEZ, Julio: Las iglesias de Nuestra Señora del Pino y las ermitas de Teror. Islas Canarias, 2008, pp. 137-141.

${ }^{30}$ CAZORLA LEÓN, Santiago y SÁNCHEZ RODRÍGUEZ, Julio: Obispos... op. cit., pp. 188-189.

${ }^{31}$ GIUDICE, Michele del: Descrizione del Real Tempio e Monastero di Santa Maria la Nuova di Monreale. Palermo, 1702, pp. 116-135. MISURACA, G.: Serie degli Arcivescovi di Cefalù. Roma, 1960, p. 51. 
Figura 1. Portada de la antigua

Real Audiencia de Sevilla.

Cuerpo inferior.

Alonso de Vandelvira. 1606.

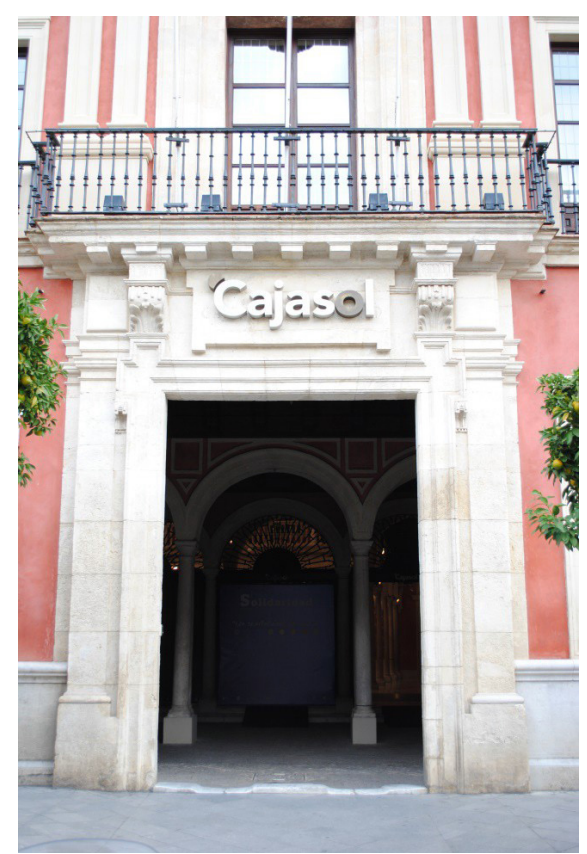

Figura 2. Portada de la antigua

Real Audiencia de Sevilla.

Cuerpo Superior.

Alonso de Vandelvira. 1606.

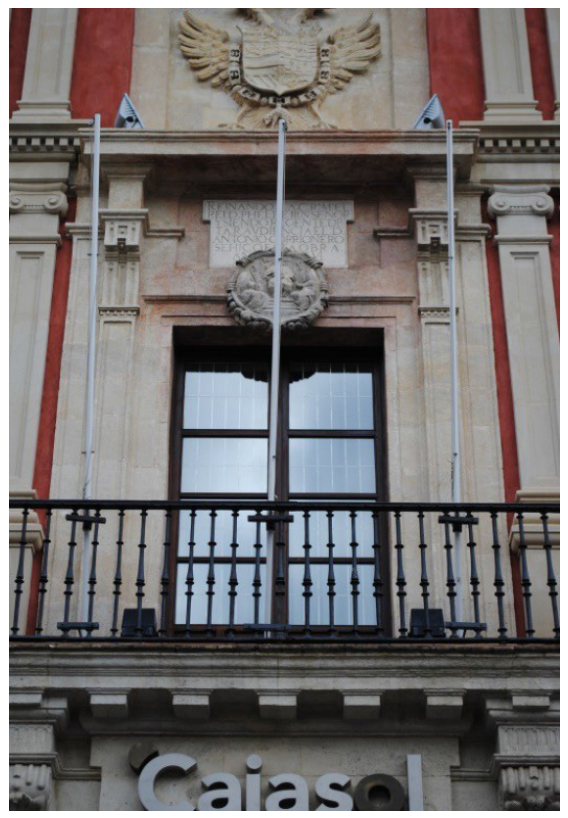




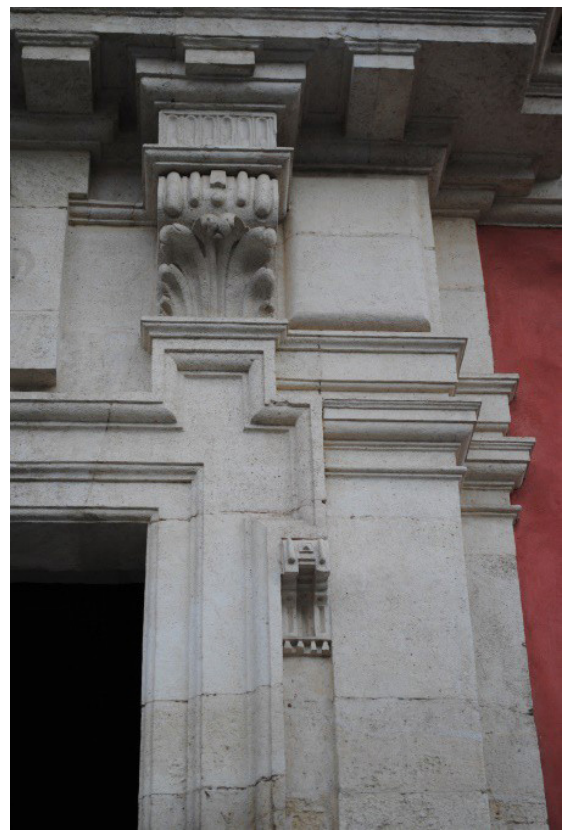

Figura 3. Portada de la antigua Real Audiencia de Sevilla. Cuerpo inferior. Alonso de Vandelvira. 1606.

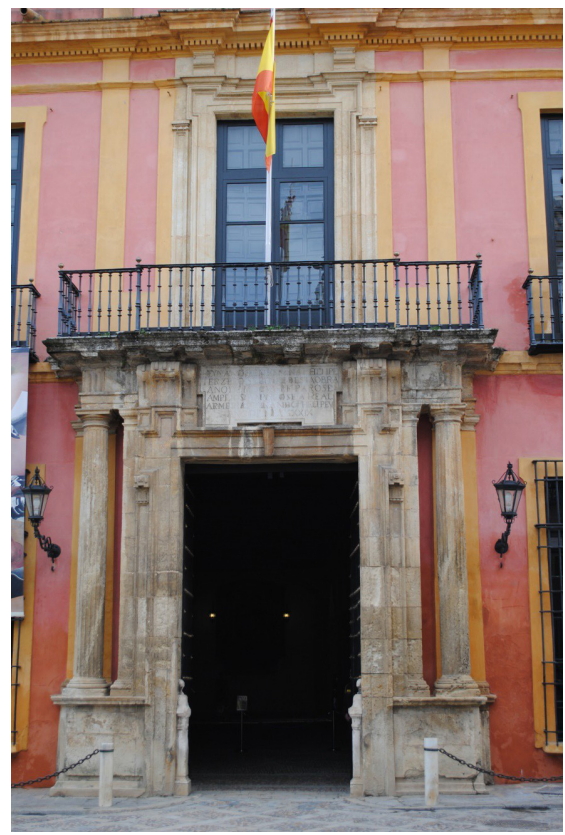

Figura 4. Portada del apeadero.

Reales Alcázares de Sevilla.

Vermondo Resta. 1607-1609. 


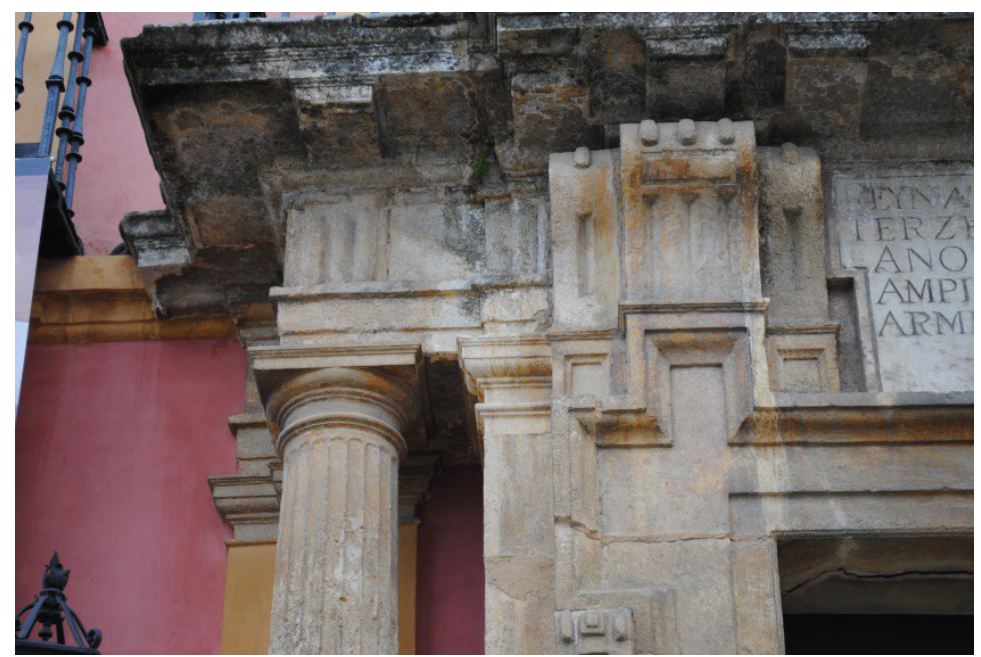

Figura 5. Portada del apeadero. Detalle.

Reales Alcázares de Sevilla. Vermondo Resta. 1607-1609.

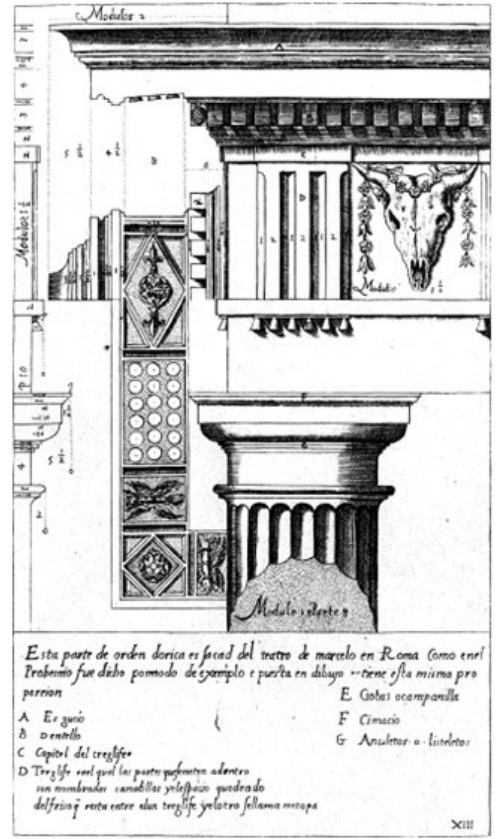

Figura 6. Orden dórico. Vignola, Regla de los cinco órdenes de arquitectura. 1593. Biblioteca de la Universidad de Sevilla. 


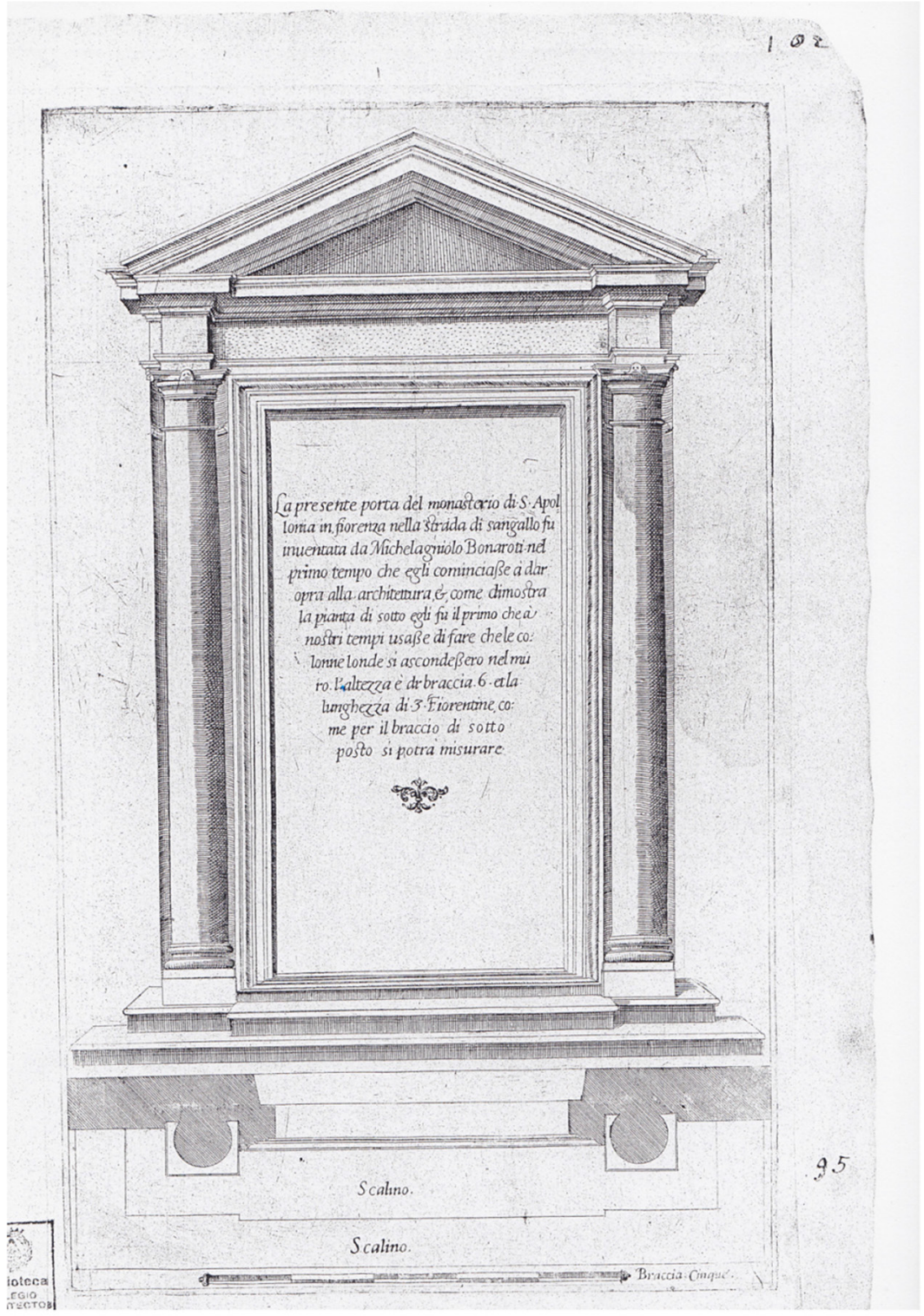

Figura 7. Puerta del monasterio de Santa Apolonia de Florencia de Miguel Ángel.

Vignola, Regola delli cinque ordini d'architettura. 1562.

Biblioteca del Colegio Territorial de Arquitectos de Valencia. 